\title{
Efficiency and Effectiveness of a Fin Having Pentagonal Cross Section Dependent on the One- Dimensional Position
}

\author{
$1^{\text {st }}$ A. W. Vidjabhakti ${ }^{1}, 2^{\text {nd }}$ P. K. Purwadi ${ }^{2}, 3^{\text {rd }}$ Sudi Mungkasi $^{3}$ \\ \{maximillian.elred@gmail.com ${ }^{1}$,pur@usd.ac.id ${ }^{2}$, sudi@usd.ac.id ${ }^{3}$ \} \\ Faculty of Science and Technology, Sanata Dharma University, Indonesia ${ }^{1,2,3}$
}

\begin{abstract}
In this paper, we investigate the influence of convection heat transfer coefficient and declivity fin angle to the efficiency and effectiveness of pentagonal fins. The temperature distribution is computed using an explicit finite difference method. The area of the fin is dependent on the one-dimensional position. Our computational experiments show that: (a) the convection heat transfer coefficient influences the efficiency and effectiveness for the steady and unsteady states, that is, the larger the coefficient leads to the smaller the efficiency and effectiveness (b) the declivity fin angle also influences the efficiency and effectiveness of the fin for the steady and unsteady states, that is, the smaller the declivity fin angle leads to the larger effectiveness both for steady and unsteady states, but the efficiency is smaller for steady state.
\end{abstract}

Keywords. A fin having pentagonal, cross section, efficiency, effectiveness

\section{Introduction}

In the field of machinery, fins are widely applied to equipment that has a function to move heat. With the fin, the surface of the object in contact with the fluid becomes larger [1]. The larger the surface area of the object, the greater the heat energy of the convection that can be moved. The presence of fins on the combustion motor cylinder, over-heat conditions on the motor fuel cylinder can be avoided. Likewise, what happens to the computer, the condition of over-heating on the processor, when the computer is working can be avoided[2]. The ability of the fin to move heat is expressed by the value of the effectiveness of the fin. Fins with high effectiveness will be able to move heat in large quantities. The effectiveness of fins is the ratio between heat that can be removed objects finned with objects without fins. In fin design, it is important to know the value of the fin effectiveness.

It is not easy to do analytical calculations for obtaining temperature distribution, heat release of fins, fin efficiency and effectiveness of fins[3], [4]. Whereas if done experimentally, the costs are relatively high, taking longer and more complicated research time. One easy and low-cost way to solve this problem is to use computational methods, one of them with an explicit finite difference method. In this paper, we shall calculate the efficiency and effectiveness of these fins using an explicit finite difference method. In addition, we investigate the influence of convection heat transfer coefficient and fin slope angle (declivity of the fin) on the efficiency and effectiveness of fins in unsteady states. 
The fin geometry that we consider has a pentagon section, with a cross section of the position function, as shown in Figure 1. The fin length is denoted L. The fin base, has the sides with length a. The thermal conductivity of the fin function is of the temperature function or $\mathrm{k}=\mathrm{k}(\mathrm{T})$. The temperature of the fluid passing through the fin and the heat transfer coefficient of convection are expressed by $\mathrm{T} \infty$ and $\mathrm{h}$.
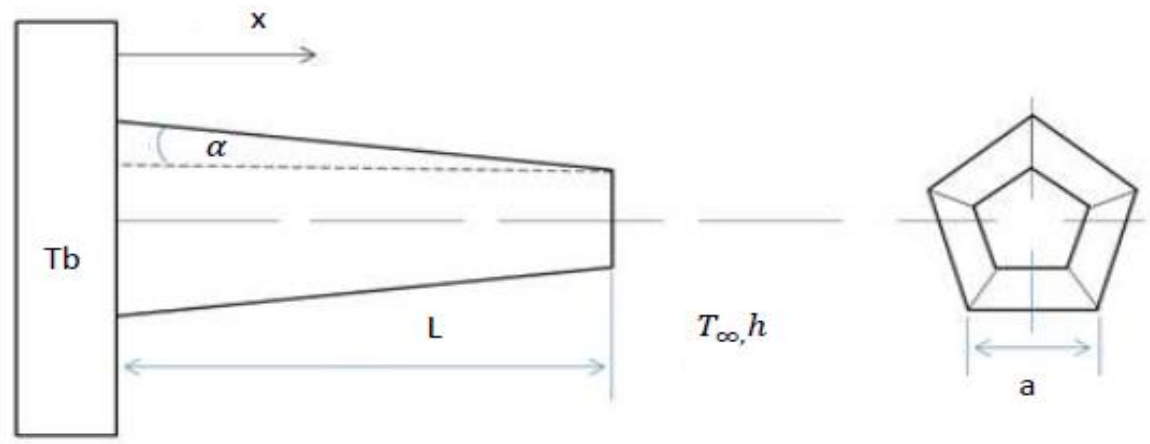

Fig. 1. Pentagonal cross-section straight geometry

In this paper we assume:

(a). Specific density and specific heat of fin material remain or do not change with temperature and their properties are uniform.

(b). The thermal conductivity of the fin material changes with respect to temperature.

(c). There is no energy generation in the fin.

(d). During the process, the fins do not change in its shape and volume.

(e). The properties of fluid, fluid temperature and convection heat transfer coefficient are constant and uniform.

(f). The fin base temperature is kept constant over time.

(g). The speed of fluid flow around the fins is considered uniform and fixed over time.

(h). The direction of heat transfer of conduction is only in the x-direction, perpendicular to the fin base (one-dimensional case).

(i). There is no heat transfer process.

To solve the problem, we use computational methods using an explicit finite difference method[5]-[7]. The problem solving was carried out in the following order: (a) searching for temperature distribution on the fin in an unsteady state (b) calculating the heat flow released by the fin in an unsteady state (c) calculating fin efficiency and effectiveness of the fin in an unsteady state. Fig 2 shows the fin that is divided into small elements called control volumes, the number of control volumes is $\mathrm{m}=100$. 


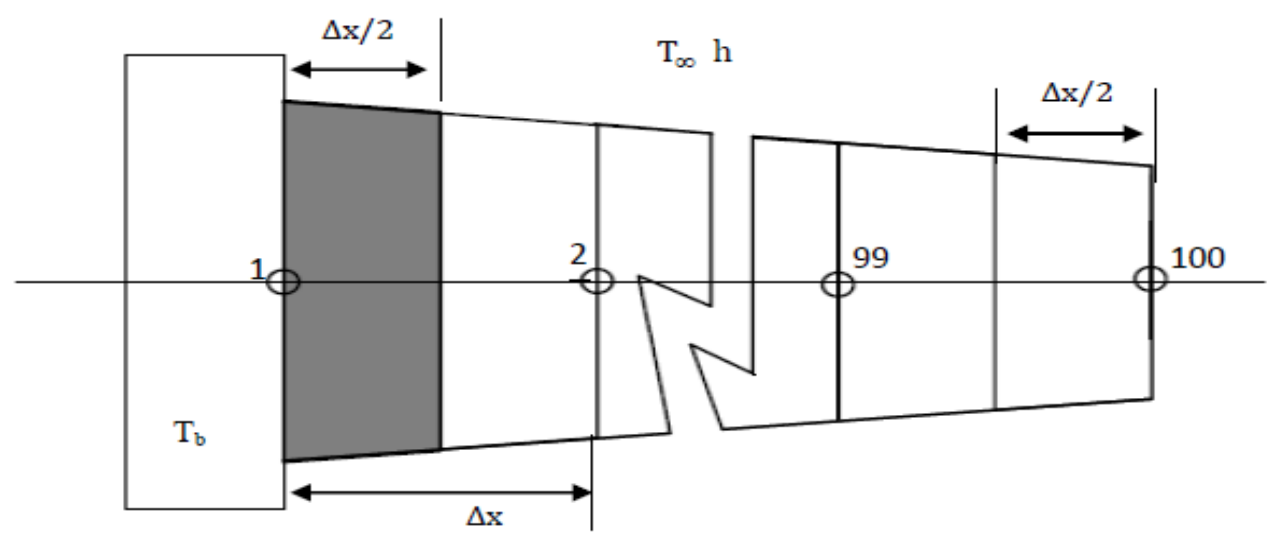

Fig. 2. Distribution of volume controls in fins, with the number of control volumes 100

\subsection{The temperature distribution of fins in an unsteady state}

At the initial conditions, the fins have a uniform temperature, equal to $T_{i}$, or can be expressed by equation (1).

$$
T(x, 0)=T_{i}^{o}=T_{i}, \quad \text { on } 0 \leq \mathrm{x} \leq \mathrm{L}, \text { for } \mathrm{t}=0 .
$$

The boundary conditions at the base of the fin or at the position of $x=0$ or at $i=1$, from time to time the temperature of the base of the fin is maintained at a fixed temperature, or by the explicit finite difference method can be expressed by equation (2).

$$
T_{i}^{n+1}=T_{b}, \quad \text { at } \mathrm{i}=1, \text { for } \mathrm{t}>0 .
$$

The boundary conditions at the tip of the fin or at $\mathrm{x}=\mathrm{L}$ or at $\mathrm{i}=\mathrm{m}$, from time to time the fin tip performs heat transfer by convection with fluid across the fin, or by different methods up to explicit ways can be expressed by equation (3).

$$
\begin{gathered}
T_{i}^{n+1}=\left(\frac{\Delta t}{\rho . c . \Delta x \cdot V_{i}}\right)\left[k_{i-1 / 2}^{n} A_{p, i-1 / 2}\left(T_{i-1}^{n}-T_{i}^{n}\right)+h \Delta x A_{p, i}\left(T_{\infty}-T_{i}^{n}\right)+\mathrm{h} \Delta x A_{s, i}\left(T_{\infty}\right.\right. \\
\left.\left.-T_{i}{ }^{n}\right)\right]+T_{i}^{n}
\end{gathered}
$$

at $\mathrm{i}=\mathrm{m}$, for $\mathrm{t}>0$.

Equation (3) has a stability condition that can be expressed by equation (4):

$$
\Delta \mathrm{t} \leq \frac{\rho \cdot c \cdot V_{\mathrm{i}} \cdot \Delta \mathrm{x}}{\left(k_{i-1 / 2}^{n} \mathrm{~A}_{\mathrm{p}, \mathrm{i}-1 / 2}\right)+\left(\text { h. } \Delta \mathrm{x} . . \mathrm{A}_{\mathrm{p}, \mathrm{i}}\right)+\left(\text { h. } . \Delta \mathrm{x} \cdot \mathrm{A}_{\mathrm{s}, \mathrm{i}}\right)}
$$


Numerical equations with the explicit finite difference method, to calculate the temperature of the control volume located between the base of the fin and the tip of the fin or at $0<\mathrm{x}<\mathrm{L}$ or at the control volume $\mathrm{i}=2,3,4, \ldots, \mathrm{m}-2, \mathrm{~m}-1$ can be expressed by equation (5).

$$
\begin{aligned}
T_{i}^{n+1}= & \frac{\Delta t}{\rho \cdot c \cdot V_{i} \cdot \Delta x}\left[k_{i-1 / 2}^{n} \cdot A_{p, i-1 / 2}\left(T_{i-1}^{n}-T_{i}^{n}\right)+k_{i+1 / 2}^{n} \cdot A_{p, i+1 / 2}\left(T_{i+1}^{n}-T_{i}^{n}\right)\right. \\
& \left.+h \cdot \Delta x \cdot A_{s, i}\left(T_{\infty}-T_{i}^{n}\right)\right]+T_{i}^{n}
\end{aligned}
$$

at $\mathrm{i}=2,3,4, \ldots, \mathrm{m}-2, \mathrm{~m}-1$, for $\mathrm{t}>0$

Equation (5) has a stability condition which is stated by equation (6):

$$
\Delta t \leq \frac{\rho . \text { c. } V_{i} \Delta x}{\left(k_{i-1 / 2}^{n} A_{p, i-1 / 2}\right)+\left(k_{i+1 / 2}^{n} A_{p, i+1 / 2}\right)+\left(h . \Delta x \cdot A_{s i}\right)}
$$

In equations (1), (2), (3), (4), (5), and (6):

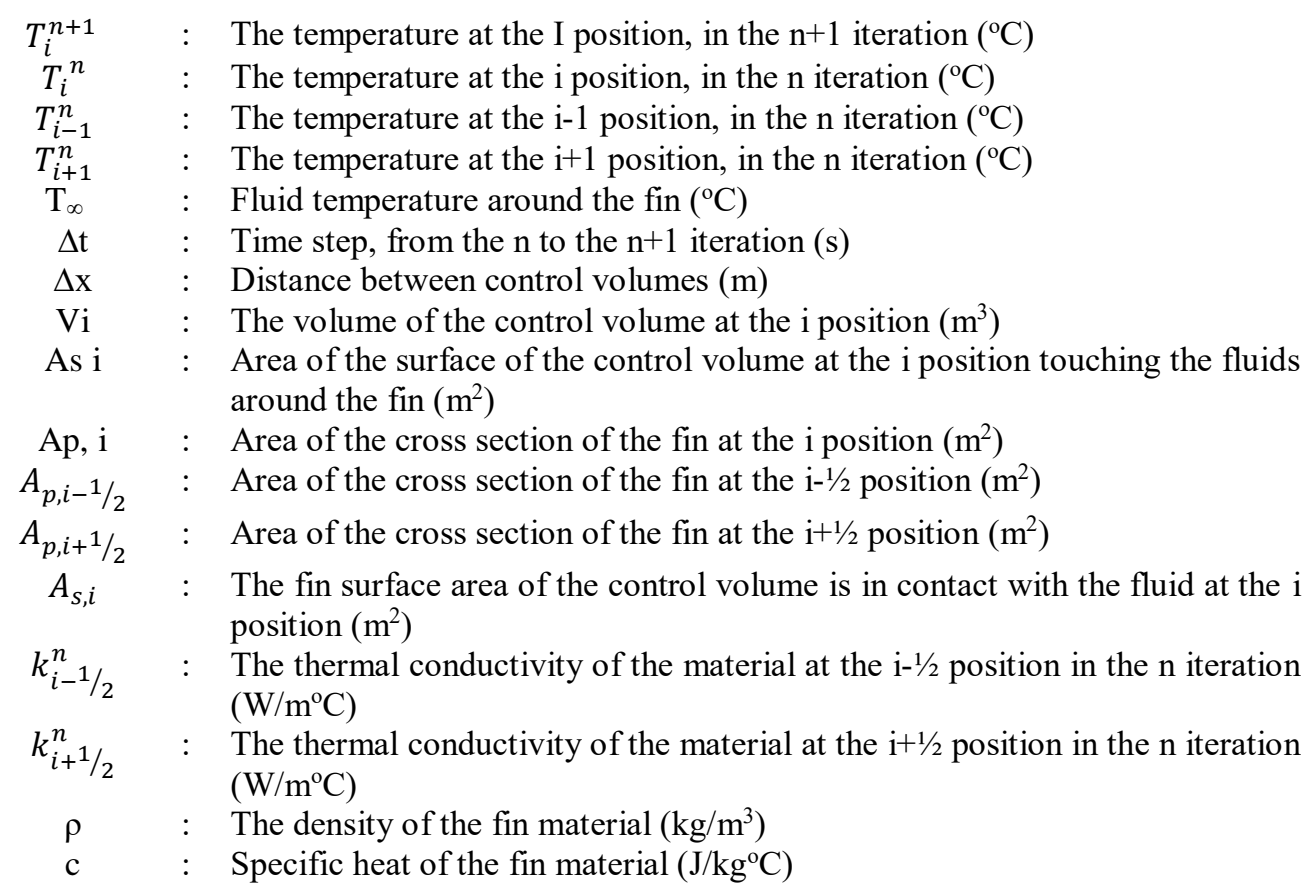

\subsection{The heat flow released by the fin is in a state of unstable}

The real heat that is released (qactual) by fins into the fluid that crosses the fin when $t=n$, can be calculated using equation (7). The ideal heat, is the maximum heat that can be released by the fin (qideal), can be calculated using equation (8). The ideal heat is calculated when the temperature of the entire surface of the fin equals the base temperature of the fin. The heat 
released by the base section of the fin, if the fin length is equal to zero (qwithout fins), can be calculated by equation (9).

$$
\begin{gathered}
q_{a c t}^{n}=h \sum_{\mathrm{i}=1}^{\mathrm{m}}\left(\mathrm{A}_{\mathrm{s}, \mathrm{i}}\left(\mathrm{T}_{\mathrm{i}}^{\mathrm{n}}-\mathrm{T}_{\infty}\right)\right) \\
q_{\text {ideal }}=\mathrm{h} \sum_{\mathrm{i}=1}^{\mathrm{m}}\left(\mathrm{A}_{\mathrm{s}, \mathrm{i}}\left(\mathrm{T}_{\mathrm{b}}-\mathrm{T}_{\infty}\right)\right)=\mathrm{h} \mathrm{A}_{\mathrm{s}}\left(\mathrm{T}_{\mathrm{b}}-\mathrm{T}_{\infty}\right) \\
q_{\text {notfin }}=\mathrm{hA}_{\mathrm{p}, 1}\left(\mathrm{~T}_{\mathrm{b}}-\mathrm{T}_{\infty}\right)
\end{gathered}
$$

\subsection{Fin effectiveness and fin efficiency in an unsteady state}

The effectiveness of fins at $\mathrm{t}=\mathrm{n}$, is the ratio between the heat of the actual fin (qactual) released at $t=n$, with the heat released if there is no fin (qwithout fins), or if the fin length is equal to 0 , which can be expressed by equation (10).

$$
\varepsilon^{n}=\frac{q_{a c t}^{n}}{q_{\text {notfin }}}=\frac{\left(\sum_{\mathrm{i}=1}^{\mathrm{m}}\left(\mathrm{A}_{\mathrm{s}, \mathrm{i}}\left(\mathrm{T}_{\mathrm{i}}^{\mathrm{n}}-\mathrm{T}_{\infty}\right)\right)\right)}{\mathrm{A}_{\mathrm{p}, 1}\left(\mathrm{~T}_{\mathrm{b}}-\mathrm{T}_{\infty}\right)}
$$

The efficiency of fins at $t=n$, is the ratio between the heat released by the actual fin at $t=$ $\mathrm{n}$, with the maximum heat that can be removed by the fin, which can be expressed by Equation (11).

$$
\eta^{n}=\frac{q_{\text {actual }}^{n}}{q_{\text {ideal }}}=\frac{\mathrm{h} \sum_{\mathrm{i}=1}^{\mathrm{m}}\left(\mathrm{A}_{\mathrm{s}, \mathrm{i}}\left(\mathrm{T}_{\mathrm{i}}^{\mathrm{n}}-\mathrm{T}_{\infty}\right)\right)}{\mathrm{h} \sum_{i=1}^{m}\left(A_{s, i}\left(\mathrm{~T}_{\mathrm{b}}-\mathrm{T}_{\infty}\right)\right)}=\frac{\sum_{\mathrm{i}=1}^{\mathrm{m}}\left(\mathrm{A}_{\mathrm{s}, \mathrm{i}}\left(\mathrm{T}_{\mathrm{i}}^{\mathrm{n}}-\mathrm{T}_{\infty}\right)\right)}{\left(A_{s}\right)\left(T_{b}-T_{\infty}\right)}
$$

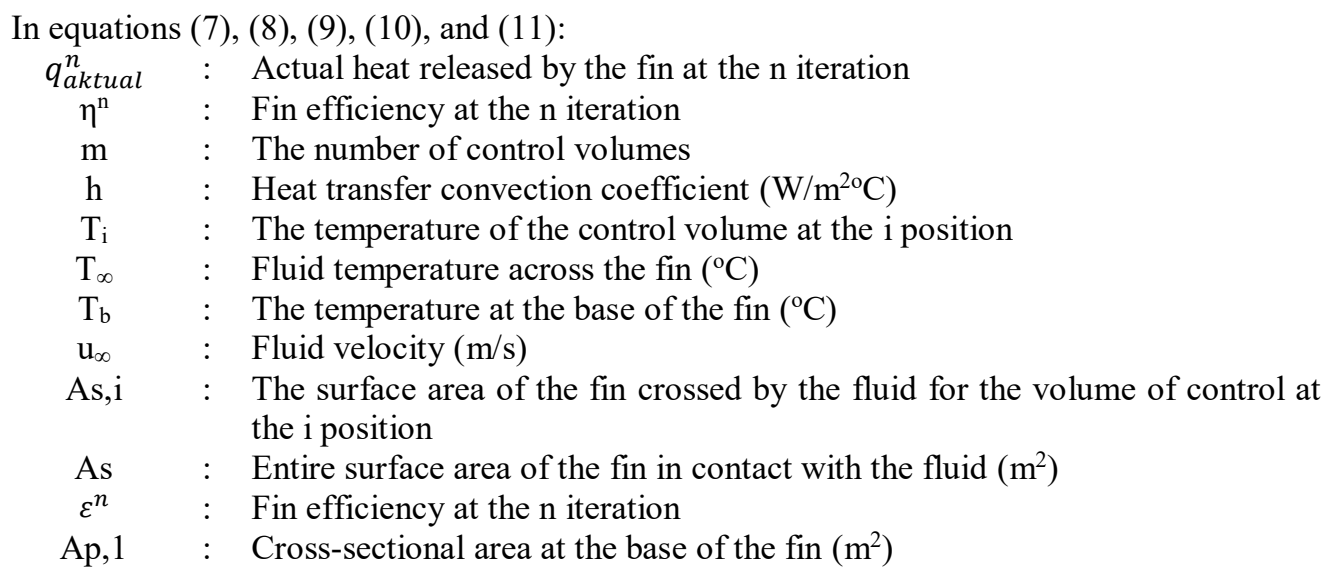

\section{Numerical method}

\subsection{Research object}


The object under consideration is a straight fin with a cross-sectional area of function position, a pentagon section, as shown in Fig 1. The initial condition of the fin has a uniform temperature as in Equation (1), with $\mathrm{Ti}=100^{\circ} \mathrm{C}$. The conditions of the base of the fin are expressed in equation (2), with $\mathrm{Tb}=100^{\circ} \mathrm{C}$. The boundary conditions at the end of the fin are bordered by the fluid in contact with the fin. In other words, the fin tip makes heat transfer by convection with fluid as expressed in equation (5). The length of the fin $\mathrm{L}=10 \mathrm{~cm}$. The amount of control volume $(\mathrm{m})$ in the fin is 100 , with the time step $\Delta \mathrm{t}=0.01$ seconds. The fluid temperature in contact with the fin $\mathrm{T} \infty=30^{\circ} \mathrm{C}$. Calculation variations include (a) the convection heat transfer coefficient $h$ and (b) the fin slope angle or the declivity of the fin. Properties of fin materials are given in Table 1.

Table 1. Properties of fin materials

\begin{tabular}{clccl}
\hline \multirow{2}{*}{ Number } & Materials & $\begin{array}{c}\rho \text { in } \\
\mathrm{kg} / \mathrm{m}^{3}\end{array}$ & $\begin{array}{c}c \text { in } \\
\mathrm{J} / \mathrm{kg}^{\circ} \mathrm{C}\end{array}$ & \multicolumn{1}{c}{$\mathrm{k}=\mathrm{k}(\mathrm{T})$ in $\mathrm{W} / \mathrm{m}^{\circ} \mathrm{C}$} \\
\hline 1 & Copper & 8930 & 387 & $\mathrm{k}=0,00002 \mathrm{~T}^{2}-0,0622 \mathrm{~T}+385,62$ \\
2 & Alumunium & 2407 & 900 & $\mathrm{k}=0,0004 \mathrm{~T}^{2}-0,0371 \mathrm{~T}+205,44$ \\
3 & Iron & 7897 & 450 & $\mathrm{k}=0,00004 \mathrm{~T}^{2}-0,0848 \mathrm{~T}+75,644$ \\
4 & Carbon steel & 7833 & 450 & $\mathrm{k}=0,00002 \mathrm{~T}^{2}-0,0454 \mathrm{~T}+55,786$ \\
5 & Silver & 10500 & 230 & $\mathrm{k}=0,0000006 \mathrm{~T}^{3}-0,0001 \mathrm{~T}^{2}-$ \\
& & & & $0,1811 \mathrm{~T}+410,54$ \\
\hline
\end{tabular}

\subsection{Calculation variations}

\subsubsection{Convection heat transfer coefficient}

For variations in convection heat transfer coefficients, we determine the convection heat transfer coefficient $\mathrm{h}$ to be (a) $50 \mathrm{~W} / \mathrm{m}^{2 \circ} \mathrm{C}$ (b) $100 \mathrm{~W} / \mathrm{m}^{2 \circ} \mathrm{C}$ (c) $250 \mathrm{~W} / \mathrm{m}^{2 \circ} \mathrm{C}$ (d) $300 \mathrm{~W} / \mathrm{m}^{2 \circ} \mathrm{C}$ and (e) $350 \mathrm{~W} / \mathrm{m}^{2 \circ} \mathrm{C}$. The fin material used is copper. The slope angle of the fin is $\alpha=3^{\circ}$. The sides of the cross section at the base of the fin have $\mathrm{a}=0.02 \mathrm{~cm}$.

\subsubsection{Fin slope angle (declivity of the fin)}

For variations in fin slope angle, the slope angle $\alpha$ of fthe in is determined for: (a) $2^{\circ}$ (b) $4^{\circ}$ (c) $6^{\circ}$ (d) $8^{\circ}$ and (e) $10^{\circ}$. The fin material used is copper. The value of cthe onvection heat transfer coefficient $\mathrm{h}=250 \mathrm{~W} / \mathrm{m}^{2 \circ} \mathrm{C}$. The sides of the cross section at the base of the fin $\mathrm{a}=0.02 \mathrm{~cm}$.

\section{Results and Discussion}

From Fig 3, we observe that convection heat transfer coefficients affect the efficiency and effectiveness of the fin. In the unsteady state until it reaches a steady state, the greater the convection heat transfer coefficients, the lower the effectiveness of the fin. Even though in equation (10), it appears that as if the effectiveness of the fin was not influenced by the convection heat transfer coefficient. However, the calculation results that the effectiveness is influenced by the convection heat transfer coefficient. This is because the convection heat transfer coefficient influences the temperature distribution produced in the fin. In equations 
(3) and (5), it appears that the calculation for temperatures in the control volumes of the fin, except at the base, is affected by the convection heat transfer coefficient.

Our computations show that the greater the convection heat transfer coefficient, the smaller the effectiveness. This means that the temperature distribution produced in the fin is lower. This leads to the closer the temperature of the fluid that crosses the fin. With a lower fin distribution, the temperature between the fin and the fluid passing through the fin gets smaller. The temperature difference that is smaller results in the actual heat released by the fins is also getting smaller. This is because the heat transfer is directly proportional to the temperature difference between the fin and the fluid[8]. Consequently, the fin effectiveness is getting smaller. With the same way of understanding, the fin efficiency is also smaller, as shown in Figure 3.
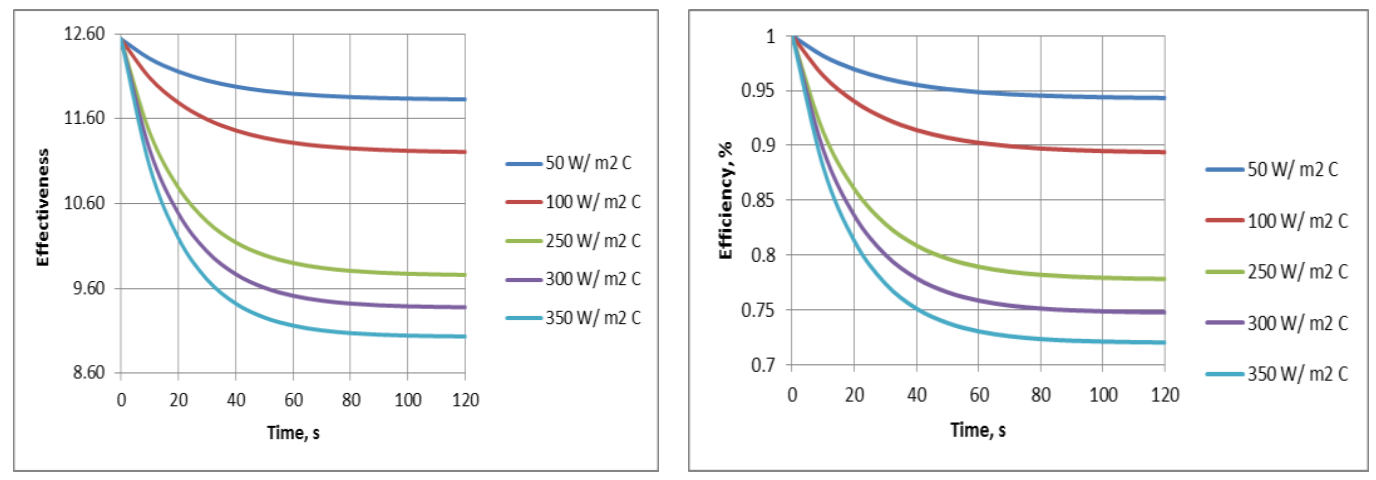

Fig. 3. Effectiveness and efficiency of fins over time, copper materials, $\alpha=3 \mathrm{o}, \mathrm{Tb}=\mathrm{Ti}=100 \mathrm{oC}$, variations of the convection heat transfer coefficient $h$

From Fig 4, it appears that the slope angle of the fin influences the effectiveness and efficiency of the fin. Although the calculation of the effectiveness of fins, as seen in equation (10), there is no effect of the slope angle, the calculation of the temperature of the fin is influenced by the magnitude of the slope angle as revealed in equations (3) and (5). If the slope of the fin changes[9], then there are also changes in the size of the fin area (Ap), the surface area of the fin in contact with the fluid (As), and the volume (V) of each control volumes. This changes, in the end, have an impact on changes in the temperature distribution that occurs in the fin. The fact is shown in this calculation, both in the steady and unsteady states, the smaller the slope angle, the greater the effectiveness of the fin. With the same understanding, the value of fin efficiency is also influenced by the size of the fin area, the fin surface area in contact with the fluid, the volume of the control volume, and the temperature distribution that occurs in the fin. In an unsteady state, the resulting phenomenon is different from that when the state is steady. In the steady state, the smaller the slope angle, the smaller the fin efficiency. 

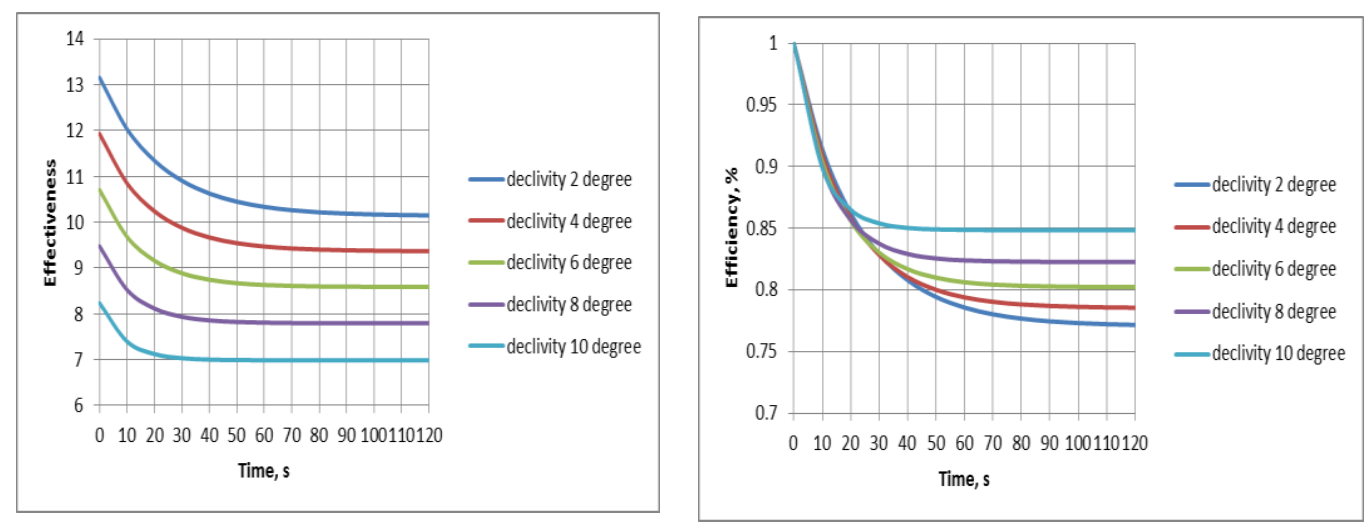

Fig. 4. Effectiveness and efficiency of fins over time, for various slope angles with the copper material, $\mathrm{Tb}=\mathrm{Ti}=100^{\circ} \mathrm{C}$, where the convection heat transfer coefficient $\mathrm{h}=250 \mathrm{~W} / \mathrm{m}^{2}{ }^{\circ} \mathrm{C}$.

\section{Conclusion}

We have investigated the efficiency and effectiveness of a fin having pentagonal crosssection dependent on the one-dimensional position. The convection heat transfer coefficient has an effect on the effectiveness and the efficiency of the fin in the steady and unsteady states, that is, the greater the convection heat transfer coefficient, the lower the effectiveness and the efficiency of the fin. The slope angle of the fin also influences the effectiveness and the efficiency of the fin. In the steady and unsteady states, the smaller the slope angle leads to the greater the effectiveness of the fins; while for the fin efficiency in the steady state, the smaller the slope angle results in the smaller the efficiency.

\section{References}

[1] H.-T. Chen, P.-L. Chen, J.-T. Horng, and Y.-H. Hung, "Design Optimization for PinFin Heat Sinks," J. Electron. Packag., vol. 127, no. 4, p. 397, 2005.

[2] B. J. Cho, P. Vandenabeele, and K. Maex, "Development of a Hexagonal-Shaped Rapid Thermal Processor Using a Vertical Tube," IEEE Trans. Semicond. Manuf., vol. 7, no. 3, pp. 345-353, 1994.

[3] K. Hashizume, R. Morikawa, T. Koyama, and T. Matsue, "Fin efficiency of serrated fins," Heat Transfer. Eng., vol. 23, no. 2, pp. 6-14, 2002.

[4] Ç. Tiris, M. Tiris, and I. E. Türe, "Effects of fin design on collector efficiency," Energy, vol. 20, no. 10, pp. 1021-1026, 1995.

[5] B. Fornberg, "Finite difference method," Scholarpedia, vol. 6, no. 10, p. 9685, 2011.

[6] R. H. Pletcher, "Finite-Difference Method," in Handbook of Numerical Heat Transfer: Second Edition, 2009, pp. 53-90.

[7] S. Sakamoto, H. Tsuru, M. Toyoda, and T. Asakura, "Finite-difference time-domain method," in Computational Simulation in Architectural and Environmental Acoustics: Methods and Applications of Wave-Based Computation, vol. 9784431544548, 2014, 
pp. 11-51.

[8] B. Roozbehani and G. H. Montazeri, "Determination of temperature distribution for annular fins with temperature-dependent thermal conductivity," Heat Transfer. Asian Res., vol. 40, no. 5, pp. 464-474, 2011.

[9] M. Sheikholeslami, S. Lohrasbi, and D. D. Ganji, "Response surface method optimization of innovative fin structure for expediting the discharging process in a latent heat thermal energy storage system containing nano-enhanced phase change material," J. Taiwan Inst. Chem. Eng., vol. 67, pp. 115-125, 2016. 